\title{
Smart Policy for Smart Vehicles: Regulatory revisions to incentivize efficient autonomous automobiles
}

\section{Martin J. Wolf}

Yale Center for Environmental Law and Policy, Yale Law School, and Yale School of the Environment, New Haven, CT https://doi.org/10.38126/ISPG180116

Corresponding author: martin.wolf@yale.edu

Keywords: autonomous vehicles; transportation policy; fuel efficiency; greenhouse gas emissions

Executive Summary: Transportation accounts for nearly $30 \%$ of the United States' annual greenhouse gas emissions and is currently the fastest growing source of emissions by economic sector. National policies are therefore needed to mitigate the climatic impact of vehicular travel. Autonomous vehicle technologies, such as adaptive cruise control and realtime route optimization, can potentially improve fuel efficiency. However, many emerging technologies remain too inefficient to meet federal fuel economy standards set by the U.S. Environmental Protection Agency and the National Highway Traffic Safety Administration. The current regulatory framework therefore hinders vehicle manufacturers from researching and developing greener autonomous technologies. In this analysis, we argue that these federal agencies should adopt policies like technology waivers, regulatory credits, environmentally preferable purchasing, and educational programs to stimulate the development of more efficient autonomous vehicle technologies. These policies would incentivize manufacturers to widely develop and deploy fuel-saving technologies that could potentially realize substantial reductions in greenhouse gas emissions.

\section{A barrier to technological development}

Improving automobile fuel efficiency standards will be a crucial step towards mitigating the United States' greenhouse gas emissions. Emissions of greenhouse gases, including from the combustion of vehicle fuels like gasoline and diesel, contribute to climatic change that harms ecosystems and infrastructure vital to the economic, public health, and national security interests of the Nation. Policies therefore need to incentivize the development and deployment of more fuel efficient vehicles. Passenger vehicles, including sedans, sport utility vehicles, and trucks, account for nearly a quarter of the Nation's carbon dioxide emissions and are currently one of the fastest growing sources of emissions (U.S. Energy Information Administration 2020). Policies therefore need to incentivize the development and deployment of more fuel efficient vehicles.
Autonomous vehicle technologies (AVTs) provide a promising pathway to reduce greenhouse gas emissions. Features that optimize navigation, traffic flow, and vehicle acceleration not only enhance safety and driver comfort, but can also theoretically minimize emissions by improving fuel efficiency if they are well designed and implemented (Zhu et al. 2019; U.S. Energy Information Administration 2017; Chen et al. 2019). Despite promising developments, many AVTs remain inefficient. Sensors, redundant safety features, and computers onboard autonomous vehicles are energy-intensive (Baxter et al. 2018). The increased electrical consumption will lead emerging autonomous vehicles to consume more fuel per mile driven than ordinary automobiles. Further, the enhanced safety features of AVTs may lead drivers to travel at greater speeds, potentially decreasing fuel economy by 5 to $22 \%$ (Taiebat et al. 2018; Wadud, MacKenzie, and Leiby 2016; Pavlov et al. 2000; Brown, Gonder, and Repac 2014). The 
increased power consumption, aerodynamic drag from external sensors, and greater driving speeds collectively contribute to increased fuel consumption of emerging AVTs (Gawron et al. 2018; Mersky and Samaras 2016; Stephens et al. 2016; Alarfaj, Griffin, and Samaras 2020). Since many systems are not yet mature enough to realize the full fuel efficiency benefits of autonomous fleets, vehicle manufacturers may therefore see an increase in their corporateaverage fuel economy (CAFE) (National Research Council 2015). These efficiency standards, promulgated by the Environmental Protection Agency (EPA) and the National Highway Traffic Safety Administration (NHTSA), permit manufacturers to develop less efficient models as long as their fleetwide average meets prescribed levels. Standards are derived by creating target efficiencies for each model based on vehicle size. Some models' actual fuel efficiency can fall below the target, so long as a manufacturer's fleetwide average meets the overall CAFE standard. Regulations impose a financial penalty on manufacturers if their automobiles do not meet CAFE standards. Manufacturers must therefore strike a balance between implementing currently inefficient AVTs in new models and meeting increasing consumer demand for larger, gas-guzzling trucks and sport utility vehicles. As consumers generally prefer sport utility vehicles and trucks over expensive self-driving cars, current fuel efficiency standards disincentivize manufacturers from implementing AVTs in their models (Libby 2020; Winston and Yan 2020).

Federal agencies should therefore overhaul regulations to incentivize the development and deployment of AVTs that demonstrate a high likelihood of increasing fuel efficiency as they mature. The EPA and the NHTSA should adopt policies like technology waivers, regulatory credits, and environmentally-preferable purchasing mandates to stimulate the development of more efficient AVTs. These policies would reward manufacturers for optimizing their smart vehicles' efficiency, ultimately realizing emissions reductions of greenhouse gases and other detrimental air pollutants in the future.

\section{Technology waivers incentivize development}

Current federal regulations can hinder the development and deployment of AVTs. By penalizing manufacturers for introducing features that increase fuel consumption, CAFE standards can disincentivize the implementation of emerging AVTs since these technologies remain inefficient (Mersky and Samaras 2016). The EPA and NHTSA should temporarily exclude or modify the regulation of autonomous vehicles' emissions to promote the development of greener AVTs. Technology waivers granted by these administrative agencies could reward good-faith efforts to increase AVT fuel efficiency by excluding vehicles equipped with experimental technology until the technology matures. Similar temporary technology waivers are authorized under the Clean Air Act (CAA) to encourage the use and development of innovative systems that reduce emissions of air pollutants (Clean Air Act (CAA) §111(j)(1)(A), $\S 111(j)(2))$. These waivers have successfully fostered innovative technologies that advance long-term reductions in emissions (Caldart and Ashford 1999; Clean Air Act Advisory Committee 2010). Federal courts have further ruled that waivers may be compulsory to allow regulated manufacturers time to demonstrate potential emissions reductions technologies (Monsanto Company v. Environmental Protection Agency, 19 F.3d 1201, 7th Cir. 1994). Technology waivers are therefore a viable policy choice to incentivize more fuel-efficient AVTs.

For instance, measurements indicate that AVTequipped models can use more energy than ordinary models due to the electrical consumption of on-board sensors and computers (Gawron et al. 2018). Further, protruding sensors can increase the aerodynamic drag of vehicles, thereby decreasing fuel efficiency. Recent estimates suggest rooftop detection and ranging sensors can increase drag by between 15 and $40 \%$, depending on sensor geometry and vehicle speed (Mohan et al. 2020). Producing these models lowers the corporate average fuel economy under current policies, penalizing manufacturers who include AVTs in their vehicles. Since electrified vehicles do not contribute to CAFE calculations, current policies negatively impact manufacturers that implement AVTs in gasoline or diesel powered vehicles, including several domestically-produced brands like Chrysler, Subaru, Cadillac, and Ford. Agencies could instead stimulate companies to develop more efficient technologies by excluding or modifying the contributions of AVT-models towards fuel economy calculations. Research indicates, for example, that emerging AVTs' electrical consumption can lead to a 3 to $20 \%$ decrease in fuel efficiency resulting from increased electrical consumption 
(Gawron et al. 2018). Early-generation autonomous vehicles may therefore be less fuel-efficient than standard automobiles. However, this fuel consumption could theoretically be more than offset by fuel efficiency gains realized from matured AVT technology that advance eco-driving behavior like platooning, resulting in a net $9 \%$ reduction in fuel consumption and greenhouse gas emissions (Gawron et al. 2018). The EPA and NHTSA should exempt the efficiency difference between emerging and mature AVTs from fuel economy calculations to incentivize the development of existing AVTs into more efficient technologies. The long-term benefits of these technology waivers could be substantial. Research suggests that AVTs can theoretically improve fuel economy by 5 to $33 \%$ if sensors are optimally designed to mitigate inefficient braking and acceleration (Thew 2007). Further analyses indicate that matured AVT technologies, like adaptive cruise control, may realize a fuel efficiency increase of up to $25 \%$ in certain traffic patterns (Lang, Schmied, and Del Re 2014).

The EPA and NHTSA should rely on their experience with other technology waivers when implementing exceptions to the CAFE standards. For instance, similar waivers are extensively used to stimulate innovation for new pollution sources under the CAA. Under §111(j), the EPA may grant flexibility in meeting emissions standards if a new technology demonstrates the potential to increase efficiency once fully developed (Clean Air Act (CAA) $\S 111(j)(1)(A)$; Foster and Brenner 2013). These provisions have enhanced the technology-forcing nature of the CAA (Randle 1979). Under previous administrations, for example, the EPA considered technology waivers as potential policy tools to spur the innovation of carbon capture technologies at fossil fuel-fired power plants (Congressional Research Service 2010). The CAA also expressly permits the EPA to grant technology waivers for nitrogen oxide emissions from automobiles, a policy design that has spurred research into improved catalytic converters (Clean Air Act (CAA) $\S 202(b)(1)(B))$, e.g., Heimrich 1997). These existing policies demonstrate technology waivers for autonomous vehicles are well within the capabilities of the EPA and NHTSA to incentivize more efficient AVTs.

\section{Emissions credits reward implementation}

Administrative agencies could further use greenhouse gas emissions credits to reward manufactures for implementing promising AVTs in their vehicles. Recent changes to CAFE regulations now enable manufacturers who do not meet prescribed CAFE standards to purchase emissions credits awarded to other manufacturers whose fuel economy is below CAFE standards (Leard and McConnell 2017). As with similar cap and trade policies enacted under the CAA, this new emissions credit market incentivizes manufacturers to develop more efficient technologies before their competitors so that they can sell their credits at a profit (Rubin, Leiby, and Greene 2009; Chan et al. 2012). To keep financial incentives to innovate high, regulators must ensure emissions limitations are stringent enough to force some manufacturers to purchase credits (McAllister 2009).

The research and development of autonomous vehicles demands substantial capital investment that can delay the innovation of more efficient technologies. Estimates suggest manufacturers spent over $\$ 50$ billion on the research and development of AVTs in 2016 alone (Kerry and Karsten 2017). The EPA and NHTSA could reward manufacturers making good-faith efforts to develop cleaner technologies with emissions credits. Firms could then decide to use, bank, loan, or sell credits as they see fit (75 Federal Register 25324 2010). In the absence of demand in the CAFE market, manufacturers may be able to sell emissions credits in the international voluntary carbon offset market as long as the credits can demonstrate additionality (McFarland 2010). An emissions credit program would therefore provide manufacturers greater regulatory freedom and economic incentive to innovate AVTs than technology waivers alone.

Consider, for example, the use of autonomous navigation that enables self-driving vehicles to avoid congested areas. Route optimization can reduce fuel consumption by up to $10 \%$ (Gilman et al. 2020). Regardless of whether fuel efficiency gains motivated manufacturers to implement autonomous navigation features, carbon offset credits should be awarded for technologies that successfully reduce emissions. A leader of autonomous navigation, Tesla Inc., manufactures exclusively electric vehicles. Carbon efficiency and emissions credits granted for energy 
savings would therefore offer Tesla-or any other manufacturer of smart electric vehicles-a compelling incentive to improve autonomous navigation technologies. Indeed, the emissions credit market is already a significant source of revenue for Tesla. In the first two quarters of 2020, it earned nearly $\$ 800$ million from selling emissions credits to other manufacturers, like Chrysler and General Motors (Tesla Inc. 2020a, 2020b; Beresford 2020). Tesla could potentially realize significant revenue from selling emissions credits awarded for implementing AVTs. For instance, assuming a 40 mile-per-gallon (mpg) CAFE standard and an emissions credit price of $\$ 100$ per mpg per vehicle, Tesla could have earned approximately $\$ 190$ million in 2020 by selling credits awarded for the implementation of fully-autonomous navigation and route optimization technology (Leard and McConnell 2017, 2020; Gilman et al. 2020; Tesla Inc. 2021). This revenue could then be invested in research, stimulating even more development in greener AVTs. Regulatory credits would therefore reduce emissions by incentivizing the application of successful technologies, especially by producers of electric vehicles.

\section{Leveraging federal purchasing power}

The immense purchasing power of the federal government can also spur private sector development of emerging technologies. The EPA should therefore leverage federal purchasing power to support manufacturers of smart vehicles and thereby promote the development of more efficient AVTs. The Environmentally Preferable Purchasing Program, founded by the Clinton Administration (58 Federal Register 203 1993) and largely continued during subsequent administrations, identifies and recommends products that federal agencies can purchase to lessen their environmental footprint. The EPA manages the Program, documenting and assisting agency efforts to implement greener purchasing strategies. For instance, the EPA provides guidance on federal purchases of greener vehicles (EPA 2020). A second mandate to foster technological innovation is given by the National Technology Transfer and Advancement Act. This Act, which is often used in conjunction with the Environmentally Preferable Purchasing Program, states that the Federal Government should use its authority and resources to help United States business to speed the development of new products and processes (15 U.S.C. $\S 37012$ ).
Together, these delineate an imperative to use federal purchasing power to advance new technologies that demonstrate reasonable potential to reduce emissions, even if the technologies are not yet mature enough to currently realize efficiency gains (White 2004; Russel 2017). By encouraging federal purchasing of vehicles equipped with AVTs, the EPA can also fulfill its obligations under the Pollution Prevention Act to promote technologies that reduce emissions at the source (42 U.S.C. \$13101 et seq.). The EPA should therefore adopt a policy to recommend the purchase of automobiles equipped with AVTs to strengthen the incentives for manufacturers that develop this technology. Similarly, the NHTSA could foster substantial reductions in greenhouse gas emissions by promoting the use of autonomous taxis and rideshare vehicles in its roadway safety protocols (Greenblatt and Saxena 2015). In addition to promoting AVTs in passenger vehicles, NHSTA should also use its convening power to foster innovations in autonomous trucking. These features would not only reduce emissions from the trucking sector, but would also potentially increase highway safety by routing trucks through less congested areas (Nasri, Bektaş, and Laporte 2018).

Manufacturers currently face demand-side disincentives to develop and implement AVTs because consumers are generally unwilling or unable to pay a premium for the technology (Nunes and Hernandez 2019; National Research Council 2015). Federal purchasing power could offset this demand gap, guaranteeing companies a market for their smart vehicles while simultaneously reducing the carbon footprint of agency operations. For example, the Smithsonian Institution has reduced the number of vehicles in its fleet by $18 \%$ and curtailed fuel consumption by $44 \%$ by purchasing cars that recommend optimized routes and driver performance (Seidel and Ye 2012). In expanding the telematics market demand, the Smithsonian has invested in the development of greener technologies while demonstrating the economic benefits of adopting existing AVTs (Yilin Zhao 2002). The EPA should similarly use its authority under the Environmentally Preferable Purchasing Program to assist other agencies in adopting AVTs. This would both reduce agencies' environmental impacts and stimulate further technological innovation.

\section{Conclusion-the potential of greener AVTs}

The widespread adoption of AVTs is not without potential pitfalls. For instance, total commuting mileage may increase due to the ease and comfort of autonomous 
transportation (Wadud, MacKenzie, and Leiby 2016). Increased mileage may therefore offset some of the emissions reductions resulting from increased fuel efficiency if autonomous vehicles are not electrified and coupled to a clean energy grid. Nevertheless, the implementation of AVTs may realize up to a $60 \%$ decrease in fuel consumption if autonomous vehicles are more fully developed and widely deployed (Stephens et al. 2016). The potential for AVTs to mitigate the climatic impact of vehicle emissions is therefore considerable.

The EPA and NHSTA should adopt several policies to incentivize the development of more efficient AVTs that

\section{References}

58 Federal Register 203. 1993. Executive Order 12873, Federal Acquisition, Recycling, and Waste Prevention.

75 Federal Register 25324. 2010. Light-Duty Vehicle Greenhouse Gas Emission Standards and Corporate Average Fuel Economy Standards, National Highway Traffic Safety Administration 40 CFR Parts 85, 86, and 600; 49 CFR Parts 531, 533,536 , et al.

Alarfaj, Abdullah F, Michael Griffin, and Constantine Samaras. 2020. "Decarbonizing US Passenger Vehicle Transport under Electrification and Automation Uncertainty Has a Travel Budget." Environ. Res. Lett 15: 940-42. https://doi.org/10.1088/1748-9326/ab7c89.

Baxter, Jared A., Daniel A. Merced, Daniel J. Costinett, Leon M. Tolbert, and Burak Ozpineci. 2018. "Review of Electrical Architectures and Power Requirements for Automated Vehicles." In 2018 IEEE Transportation Electrification Conference and Expo (ITEC), 944-49. IEEE. https://doi.org/10.1109/ITEC.2018.8449961.

Beresford, C. 2020. "Other Automakers Paid Tesla a Record \$428 Million Last Quarter." Car and Driver, July 22, 2020.

Brown, Austin, Jeffrey Gonder, and Brittany Repac. 2014. "An Analysis of Possible Energy Impacts of Automated Vehicles." Road vehicle automation, 137-53. https://doi.org/10.1007/978-3-31905990-7_13.

Caldart, Charles C., and Nicholas A. Ashford. 1999. "Negotiation as a Means of Developing and Implementing Environmental and Occupational Health and Safety Policy." Harvard Environmental Law Review 23 (1): 141-202. reduce the greenhouse gas emissions of vehicular travel. These strategies include leveraging technology waivers, regulatory credits, and federal purchasing power. The combination of smart regulations and smart technology promises great reductions in the transportation sector's greenhouse gas emissions. More fuel-efficient technologies will not only yield large climatic benefits, but also save consumers money and make the Nation less dependent on foreign fossil fuels (Executive Office of the President 2010).

Chan, Gabriel, Robert Stavins, Robert Stowe, and Richard Sweeney. 2012. "The SO2 Allowance Trading System and the Clean Air Act Amendments of 1990: Reflections on Twenty Years of Policy Innovation." Cambridge, MA. https://doi.org/10.3386/w17845.

Chen, Yuche, Jeffrey Gonder, Stanley Young, and Eric Wood. 2019. "Quantifying Autonomous Vehicles National Fuel Consumption Impacts: A Data-Rich Approach." Transportation Research Part A: Policy and Practice 122 (April): 134-45. https://doi.org/10.1016/j.tra.2017.10.012.

Clean Air Act Advisory Committee. 2010. "Permits, New Source Review and Toxics Subcommittee, Climate Change Work Group, Phase II Report."

Congressional Research Service. 2010. "EPA's BACT Guidance for Greenhouse Gases from Stationary Sources." www.crs.gov.

EPA (United States Environmental Protection Agency). 2020. "Green Vehicle Guide." www.epa.gov/greenvehicles

Executive Office of the President. 2010. "National Security Strategy of the United States." Washington, DC.

Foster, Jody, and Rob Brenner. 2013. "Clean Air and Technology Innovation: Working Concepts for Promoting Clean Technology Innovation Under the Clean Air Act NI R 13-05." Durham, NC.

Gawron, James H., Gregory A. Keoleian, Robert D. De Kleine, Timothy J. Wallington, and Hyung Chul Kim. 2018. "Life Cycle Assessment of Connected and Automated Vehicles: Sensing and Computing Subsystem and Vehicle Level Effects." Environmental Science \& Technology 52 (5): 3249-56. https://doi.org/10.1021/acs.est.7b04576. 
Gilman, Ekaterina, Satu Tamminen, Anja Keskinarkaus, Theodoros Anagnostopoulos, Xiang Su, Susanna Pirttikangas, and Jukka Riekki. 2020. "Fuel Consumption Analysis of Driven Trips with Respect to Route Choice." In 2020 IEEE 36th International Conference on Data Engineering Workshops (ICDEW), 40-47. IEEE. https://doi.org/10.1109/ICDEW49219.2020.000 $-9$.

Greenblatt, Jeffery B., and Samveg Saxena. 2015. "Autonomous Taxis Could Greatly Reduce Greenhouse-Gas Emissions of US Light-Duty Vehicles." Nature Climate Change 5 (9): 860-63. https://doi.org/10.1038/nclimate2685.

Heimrich, Martin J. 1997. "Demonstration of Lean NOx Catalytic Converter Technology on a Heavy-Duty Diesel Engine." SAE transactions Jan.: 282-292. https://doi.org/10.4271/970755.

Kerry, Cameron F., and Jack Karsten. 2017. "Gauging Investment in Self-Driving Cars." https://www.brookings.edu/research/gauginginvestment-in-self-driving-cars/.

Lang, Dominik, Roman Schmied, and Luigi Del Re. 2014. "Prediction of Preceding Driver Behavior for Fuel Efficient Cooperative Adaptive Cruise Control." SAE International Journal of Engines 7 (1): 201401-0298. https://doi.org/10.4271/2014-01$\underline{0298 .}$.

Leard, Benjamin, and Virginia McConnell. 2017. "New Markets for Credit Trading under US Automobile Greenhouse Gas and Fuel Economy Standards."

Leard, Benjamin, and Virginia McConnell. 2020. "Interpreting Tradable Credit Prices in Overlapping Vehicle Regulations."

Libby, Tom. 2020. "New Vehicle Registrations Show Record Share Levels for SUVs | IHS Markit." IHS Markit, October 6, 2020. https://ihsmarkit.com/research-analysis/newvehicle-registrations-show-record-share-levelsfor-suvs.html.

McAllister, Lesley K. 2009. "The Overallocation Problem In Cap-And-Trade: Moving Toward Stringency." Columbia Journal of Environmental Law 34 (2): 395-445. http://ssrn.com/abstract=1276405.

McFarland, B.J. 2010. "Carbon Reduction Projects and the Concept of Additionality." Sustainable Development Law \& Policy 11: 15 - 18.

Mersky, Avi Chaim, and Constantine Samaras. 2016. "Fuel Economy Testing of Autonomous Vehicles." Transportation Research Part C: Emerging Technologies 65 (April): $31-48$. https://doi.org/10.1016/j.trc.2016.01.001.

Mohan, Aniruddh, Shashank Sripad, Parth Vaishnav, and Venkatasubramanian Viswanathan. 2020. "TradeOffs between Automation and Light Vehicle Electrification." Nature Energy 5 (7): 543-49. https://doi.org/10.1038/s41560-020-0644-3.
Nasri, Moncef Ilies, Tolga Bektaș, and Gilbert Laporte. 2018. "Route and Speed Optimization for Autonomous Trucks." Computers \& Operations Research 100 (December): 89-101. https://doi.org/10.1016/j.cor.2018.07.015.

National Research Council. 2015. Cost, Effectiveness, and Deployment of Fuel Economy Technologies for Light-Duty Vehicles. Washington, D.C.: National Academies Press. https://doi.org/10.17226/21744.

Nunes, Ashley, and Kristen Hernandez. 2019. "The Cost of Self-Driving Cars Will Be the Biggest Barrier to Their Adoption." Harvard Business Review, January 31, 2019. https://hbr.org/2019/01/thecost-of-self-driving-cars-will-be-the-biggestbarrier-to-their-adoption.

Pavlov, Alexander A, James F Kasting, Lisa L Brown, Kathy A Rages, and Richard Freedman. 2000. "Greenhouse Warming by CH 4 in the Atmosphere of Early Earth." Journal of Geophysical Research 105 (11): 911-81. https://doi.org/10.1029/1999JE001134

Randle, R.V. 1979. "Forcing Technology: The Clean Air Act Experience." The Yale Law Journal 88: 1713-34.

Rubin, Jonathan, Paul N. Leiby, and David L. Greene. 2009. "Tradable Fuel Economy Credits: Competition and Oligopoly." Journal of Environmental Economics and Management 58 (3): 315-28. https://doi.org/10.1016/j.jeem.2009.05.002.

Russel, Trevor. 2017. Greener Purchasing: Opportunities and Innovations. New York: Routledge. https://books.google.com/books?hl=en\&lr=\&id= YGRQDwAAQBAJ\&oi=fnd\&pg=PP1\&dq=Russel,+ T.,+ed.+Greener+purchasing:+Opportunities+and + innovations\&ots $=$ br f9EAAOH\&sig $=4$ rZ8CrvLm b24JUIwSa4Fk3fu05U\#v=onepage \&q=Russel $\% 2$ C T. $\% 2 \mathrm{C}$ ed. Greener purchasing $\% 3 \mathrm{~A}$ Opportunities.

Seidel, Stephen, and Jason Ye. 2012. "Leading by Example: Using Information and Communication Technologies to Achieve Federal Sustainability Goals."

Stephens, T. S., Jeff Gonder, Yuche Chen, Z. Lin, C. Liu, and D. Gohlke. 2016. "Estimated Bounds and Important Factors for Fuel Use and Consumer Costs of Connected and Automated Vehicles." Golden, CO (United States). https://doi.org/10.2172/1334242.

Taiebat, Morteza, Austin L. Brown, Hannah R. Safford, Shen $\mathrm{Qu}$, and Ming Xu. 2018. "A Review on Energy, Environmental, and Sustainability Implications of Connected and Automated Vehicles." Environmental Science \& Technology, September, acs.est.8b00127.

https://doi.org/10.1021/acs.est.8b00127.

Tesla Inc. 2020a. "Q1 2020 Update."

Tesla Inc. 2020b. "Q2 2020 Update." 
Tesla Inc. 2021. "Q4 2020 Update."

Thew, R. 2007. "United Evidence and Research Strategy: Driving Standards Agency."

U.S. Energy Information Administration. 2017. "Study of the Potential Energy Consumption Impacts of Connected and Automated Vehicles." Washington, DC. www.eia.gov.

U.S. Energy Information Administration. 2020. "Annual Energy Outlook 2020 with Projections to 2050." Washington, DC. www.eia.gov/aeo.

Wadud, Zia, Don MacKenzie, and Paul Leiby. 2016. "Help or Hindrance? The Travel, Energy and Carbon Impacts of Highly Automated Vehicles." Transportation Research Part A: Policy and Practice $86 \quad$ (April): $1-18$. https://doi.org/10.1016/j.tra.2015.12.001.

White, William J. 2004. "Measuring Benefits from the National Technology Transfer and Advancement Act, RTI Project Number 08628 ." Research Triangle Park, NC.
Winston, Clifford, and Jia Yan. 2020. "Vehicle Size Choice and Automobile Externalities: A Dynamic Analysis." Journal of Econometrics, August. https://doi.org/10.1016/i.jeconom.2020.07.032.

Yilin Zhao. 2002. "Telematics: Safe and Fun Driving." IEEE Intelligent Systems 17 (1): 10-14. https://doi.org/10.1109/5254.988442.

Zhu, Lei, Jeffrey Gonder, Eric Bjarkvik, Mitra Pourabdollah, and Bjorn Lindenberg. 2019. "An Automated Vehicle Fuel Economy Benefits Evaluation Framework Using Real-World Travel and Traffic Data." IEEE Intelligent Transportation Systems $\begin{array}{lll}\text { Magazine } & 11 & \text { (3): } 29-41 .\end{array}$ https://doi.org/10.1109/MITS.2019.2919537.

Martin Wolf is a postdoctoral associate at the Yale Center for Environmental Law and Policy and the Principal Investigator of the 2022 Environmental Performance Index. He received a Ph.D. in Climate Science from the Massachusetts Institute of Technology in 2020. His research focused on the climatic impacts of industrial pollutant emissions. Prior to joining Yale, he was a Mirzayan Science \& Technology Policy Fellow at the U.S. National Academy of Sciences' Board on Environmental Change and Society in Washington, DC.

\section{Acknowledgements}

This work is based on research performed in Jody Freeman's Climate Change Law and Policy seminar at Harvard Law School. The author would like to thank Professor Freeman for accepting him into the seminar and for providing background materials on transportation policy.

\section{Disclaimer}

The views expressed herein are those of the author alone and do not necessarily represent endorsement by the Yale Center for Environmental Law and Policy or Yale University. 